\title{
Development of a Simple Fe(II) Ion Colorimetric Sensor from the Immobilization of 1,10-Phenanthroline In Alginate/Pectin Film
}

\author{
Nindya Tri Muliawati, Dwi Siswanta ${ }^{*}$, and Nurul Hidayat Aprilita \\ Department of Chemistry, Faculty of Mathematics and Natural Sciences, Universitas Gadjah Mada, \\ Sekip Utara, 55281 Yogyakarta, Indonesia
}

${ }^{*}$ Corresponding author:

tel: $+62-8157951198$

email:dsiswanta@ugm.ac.id

Received: June 9, 2020

Accepted: October 6, 2020

DOI: $10.22146 /$ ijc.56759

\begin{abstract}
An optical analytical sensor was proposed based on the complexation reactions of 1,10-phenanthroline derivative in aqueous solutions. This study aims to synthesize a metal ion sensor for detecting $\mathrm{Fe}(\mathrm{ll})$ ion from the immobilization of 1,10phenanthroline compound in alginate/pectin film. This was carried out by characterizing the films using the Fourier-transform infrared spectrometry (FT-IR) and scanning electron microscope (SEM). The determination of the optimal condition for Fe(II) ion detection and validation of the parameters was conducted by measuring the absorbance of the films using a UV-Vis spectrophotometer. After the addition of Fe(II) ion, the color of the alginate/pectin-phenanthroline film changed from transparent yellow to orangered, showing its potential as a visual colorimetric sensor for iron(II) ion. It was found that the optimum condition for $\mathrm{Fe}(\mathrm{II})$ ion sensing was at $513 \mathrm{~nm}$ after $2 \mathrm{~min}$ of detection at pH 2. The alginate/pectin-phenanthroline film had good linearity, precision, selectivity, and accuracy with a detection limit as low as $0.446 \mathrm{mg} \mathrm{L}^{-1}$, which was remarkable.
\end{abstract}

Keywords: alginate/pectin film; colorimetric sensor; $\mathrm{Fe}(\mathrm{II})$ ion detection; 1,10phenanthroline

\section{- INTRODUCTION}

Iron $(\mathrm{Fe})$ is one of the most essential heavy metals in the industrial field due to its low cost, sturdiness, and ease of mass production, which has made it an ideal choice for transportation, mining, and construction. However, the disposal of iron waste from various industrial activities, such as mining sports, hydrometallurgy, foundries, and smelters [1] into the aquatic environment, causes some adverse effects not only to the environment but also to human health. In the form of Fe(II) and Fe(III) ions, they are indispensable as the micronutrient for living organisms; however, they cause problems for ecosystems and human health at higher concentrations. According to the WHO regulation, the limit for $\mathrm{Fe}$ (II) and $\mathrm{Fe}$ (III) ions should be less than $0.3 \mathrm{mg} \mathrm{L}^{-1}$ in municipal drinking water [2]. When their amounts exceed this limit, they generate an unpleasant taste and odor in drinking water, causing tissue damage in humans and also blockage of pipes or transmission lines in the processing industry due to the formation of iron hydroxide precipitations [3].
Several analytical methods have been established for the determination of $\mathrm{Fe}$ ions concentration in environmental samples, such as atomic absorption spectrometry (AAS) [4], UV-Visible spectrophotometry [5], inductively coupled plasma-optical emission spectrometry (ICP-OES), and inductively coupled plasma-mass spectrometry (ICP-MS) [6]. However, these methods still have several limitations, such as complicated protocols, time and cost consumption, and requiring a specific technique. Therefore, a simple method for the determination of $\mathrm{Fe}$ ions is highly required. The colorimetric sensor becomes an extremely enticing method since it is easy to read using a low-cost portable instrument and even naked-eye observation [7].

Colorimetric methods are carried out using specific chemicals which are immobilized in a suitable matrix, where they selectively bind the analytes and produce characteristic color change [8]. The optical sensors for the analysis of $\mathrm{Fe}(\mathrm{II})$ ions have been previously developed using PVC-based membranes as a 
matrix for immobilizing 2,6-bis(carboxamide methyl ester) as the chromogenic reagent [9]. However, these methods required complicated reagent synthesis processes. Similarly, a simple optical sensor was developed using the polypropylene-based paper strip with the immobilized 1,10-phenanthroline reagent [3]. However, this method uses a synthetic polymer-based matrix, which is less environmentally friendly.

In this study, a new film sensor for $\mathrm{Fe}(\mathrm{II})$ ion determination using a functionalized, environmentally friendly membrane was developed. This comprises of pectin, a polysaccharide composed of $\mathrm{D}$-galacturonic acid monomers forming a long chain through 1,4-glycoside bonds, and commonly found on the plant cell walls [10]. And alginate, a hydrophilic polysaccharide composed of bonds $(1,4)$ between $\beta$-D-mannuronate $(M)$ and $\alpha$-Lguluronate $(\mathrm{G})$ copolymers, and commonly found in seaweed [11]. Both biomaterials are capable of forming strong gels in the presence of divalent cations, such as $\mathrm{Ca}^{2+}$ ion. The combination of these polymers provides unique properties that are strong, water-resistant, and are widely used in several fields as a carrier matrix [12]. Then, the 1,10-phenanthroline reagent is immobilized on the alginate/pectin film to obtain the functionalized optical membrane that provides a rapid, sensitive, and simple alternative method for determining $\mathrm{Fe}$ (II) in the aqueous sample.

\section{- EXPERIMENTAL SECTION}

\section{Materials}

Sodium alginate was obtained from Sigma Aldrich. Mannuronic to the guluronic acid ratio (M/G) of alginate was 1.56. High methoxyl content pectin was procured from Bintang Utama Sentosa Inc. (Bekasi, Indonesia). Ethanol (99.9\%) and 1,10-phenanthroline (99.9\%) were purchased from Merck. Stock solution $\left(100 \mathrm{mg} \mathrm{L}^{-1}\right)$ of $\mathrm{Fe}$ (II) ion $100 \mathrm{~mL}$ was prepared from the solid $\left(\mathrm{NH}_{4}\right)_{2} \mathrm{Fe}\left(\mathrm{SO}_{4}\right)_{2} \cdot 6 \mathrm{H}_{2} \mathrm{O}$ (Merck) $0.07 \mathrm{~g}$, which was dissolved in distilled water by adding $0.50 \mathrm{~g}$ of hydroxylamine hydrochloride $99.9 \%$ (Merck) and $5 \mathrm{~mL}$ of $\mathrm{H}_{2} \mathrm{SO}_{4}$ (Merck) $2 \mathrm{M}$. Standard solution $1000 \mathrm{mg} \mathrm{L}{ }^{-1}$ of $\mathrm{Cu}^{2+}, \mathrm{Zn}^{2+}, \mathrm{Co}^{2+}$, $\mathrm{Fe}^{3+}, \mathrm{Pb}^{2+}, \mathrm{Ni}^{2+}, \mathrm{Ca}^{2+}$, and $\mathrm{Mg}^{2+}$ (Merck) were used for the interference study and prepared using distilled water from CV. Progo Mulyo (Yogyakarta, Indonesia). All chemical used were analytical reagent grade without further purification process.

\section{Instrumentation}

The color absorbance of sensor films was determined using a UV-Vis Spectrophotometer (Shimadzu UV-1800). The prepared membrane was characterized by a Fourier Transform-Infrared Spectrophotometer (Shimadzu IR Prestige 21), while the morphology of surface membranes was analyzed using a Scanning Electron Microscope (JOEL type JSM-6701F).

\section{Procedure}

\section{Synthesis of alginate/pectin film immobilized 1,10- phenanthroline}

The alginate/pectin-phenanthroline film was made by mixing $0.05 \mathrm{~g}$ alginate and $0.20 \mathrm{~g}$ pectin in $10 \mathrm{~mL}$ of distilled water. The homogeneous solution was then poured into a petri dish $(60 \mathrm{~mm})$ and dried at $55^{\circ} \mathrm{C}$ for $16 \mathrm{~h}$. The alginate/pectin film was immersed for $24 \mathrm{~h}$ in a solution of $2 \%(\mathrm{w} / \mathrm{v}) \mathrm{CaCl}_{2}$ to allow the crosslinking reaction. The crosslinking alginate/pectin film was then immersed in $5 \mathrm{~mL} \mathrm{1,10-phenanthroline} \mathrm{for} 24 \mathrm{~h}$. After that, the obtained film was dried at room temperature and was used for further characterization. The thickness of the alginate/pectin-phenanthroline film was $0.029 \pm$ $0.005 \mathrm{~mm}$, with an average weight of $0.1258 \mathrm{~g}$. For all the experiments, the film was cut into $1 \times 1 \mathrm{~cm}^{2}$ size and used.

\section{Optimization of the measurement parameters}

Colorimetric detection of $\mathrm{Fe}(\mathrm{II})$ ions using alginate/pectin-phenanthroline film was carried out by immersing the film in $2 \mathrm{~mL}$ of $\mathrm{Fe}$ (II) solution for $2 \mathrm{~min}$. Various concentration (2-10 $\left.\mathrm{mg} \mathrm{L}^{-1}\right)$ of $\mathrm{Fe}(\mathrm{II})$ ion was adjusted at pH 1-6 using $0.1 \mathrm{M} \mathrm{HCl}$ and $0.1 \mathrm{M} \mathrm{NaOH}$ solutions. The maximum absorption wavelength of the alginate/pectin film was measured by scanning the absorbance of the film at 450-600 nm using a UVVisible spectrophotometer. The $\lambda_{\max }$ was used to obtain the amount of phenanthroline to be added during the synthesis of the alginate/pectin film by varying the concentration of 1,10 -phenanthroline $(0.1-0.3 \% \mathrm{w} / \mathrm{v})$. The interference study of alginate/pectin-phenanthroline film was investigated by performing the detection of 
$\mathrm{Fe}(\mathrm{II})$ ion in the presence of other metal ions $\left(\mathrm{Cu}^{2+}, \mathrm{Zn}^{2+}\right.$, $\mathrm{Co}^{2+}, \mathrm{Fe}^{3+}, \mathrm{Pb}^{2+}, \mathrm{Ni}^{2+}, \mathrm{Ca}^{2+}$, and $\mathrm{Mg}^{2+}$ ) under optimum condition.

\section{Film alginate/pectin sensing ability}

The different concentrations $(0,2.0,4.0,6.0,8.0$, and $10.0 \mathrm{mg} \mathrm{L}^{-1}$ ) of $\mathrm{Fe}(\mathrm{II})$ solutions were tested using a film sensor in triplicate to obtain the calibration curve. The detection limit is calculated using the $3 \mathrm{~s} / \mathrm{S}$ criterion, where ' $s$ ' is the standard deviation of the absorbance of 10 blank alginate/pectin film, and ' $S$ ' is the slope of the linear calibration curve [3]. The accuracy of the film sensor is determined based on the \% recoveries of $\mathrm{Fe}$ (II) concentration added into the tap water sample. The tap water sample from the Laboratory of Analytical Chemistry, Faculty of Mathematics and Natural Sciences, Universitas Gadjah Mada, Yogyakarta, Indonesia, was used as a real water sample. The tap water was collected in a $1.5 \mathrm{~L}$ plastic bottle and was added with $50 \mathrm{~mL}$ of $\mathrm{H}_{2} \mathrm{SO}_{4} 2 \mathrm{M}$ and $5.0 \mathrm{~g}$ hydroxylamine hydrochloride. The sample was filtrated using Whatman filter paper 42. Fe(II) solution $100 \mathrm{mg} \mathrm{L}^{-1}$ $(0.20,0.50$, and $1.00 \mathrm{~mL})$ was spiked into the tap water sample in a $10 \mathrm{~mL}$ volumetric flask. All of the tap water samples were examined using the alginate/pectin film. The absorbance of the film was measured using a UVVisible spectrophotometer under optimum condition. The $\%$ recoveries are calculated by comparing the concentration of $\mathrm{Fe}$ (II) obtained from the measurement with the concentration of $\mathrm{Fe}(\mathrm{II})$ added in the sample.

\section{- RESULTS AND DISCUSSION}

\section{FTIR Characterization of Alginate/Pectin- Phenanthroline Film}

The FTIR spectra of alginate/pectin-phenanthroline film and the initial reagents were shown in Fig. 1. The spectrum of sodium alginate (see Fig. 1(a)) had a broad peak at $3320 \mathrm{~cm}^{-1}$ due to the stretching of $\mathrm{O}-\mathrm{H}$ bond, while the sharp peaks between 1584-1413 $\mathrm{cm}^{-1}$ were attributed to the asymmetric and symmetrical vibration of $\mathrm{COO}^{-}$respectively [13]. The FTIR spectrum of pectin (see Fig. 1(b)) had two bands that were associated with the stretching vibration of the carbonyl group $(\mathrm{C}=\mathrm{O})$ in the $1800-1500 \mathrm{~cm}^{-1}$ region. The band at $1731 \mathrm{~cm}^{-1}$ was assigned to the methyl ester group $\left(-\mathrm{COOCH}_{3}\right)$, while the one observed at $1634 \mathrm{~cm}^{-1}$ originated from the asymmetric vibration of the carbonyl group in the carboxylate ion $\left(-\mathrm{COO}^{-}\right)$. The bands around $1065 \mathrm{~cm}^{-1}$ were associated with the stretching of the $\mathrm{C}-\mathrm{O}-\mathrm{C}$ bond [14].

The characteristic peaks of 1,10-phenanthroline commonly occur at $1620-1400 \mathrm{~cm}^{-1}$, which were attributed to the stretching of $\mathrm{C}=\mathrm{C}$ and $\mathrm{C}=\mathrm{N}$ in the aromatic ring of phenanthroline [15] (see Fig. 1(c)). Meanwhile, a broad water band in the region of $3400 \mathrm{~cm}^{-1}$ was usually present on the FTIR spectrum of phenanthroline due to the highly hygroscopic nature of phenanthroline [16].

The crosslinking process with $\mathrm{Ca}^{2+}$ ions caused an obvious shift of $-\mathrm{COO}^{-}$asymmetric and symmetric stretching to higher wavenumbers in the alginate/pectin-phenanthroline spectrum (Fig. 1(d)). This indicated the formation of an ionic bond between $\mathrm{COO}^{-}$from alginate and pectin and $\mathrm{Ca}^{2+}$ in order to form an "egg-box structure" [12]. The non-crosslinked alginate/pectin film containing the negatively charged carboxyl interacted with the positively charged proteins through electrostatic interaction [17]. Therefore, the protonated 1,10-phenanthroline, which was the positively

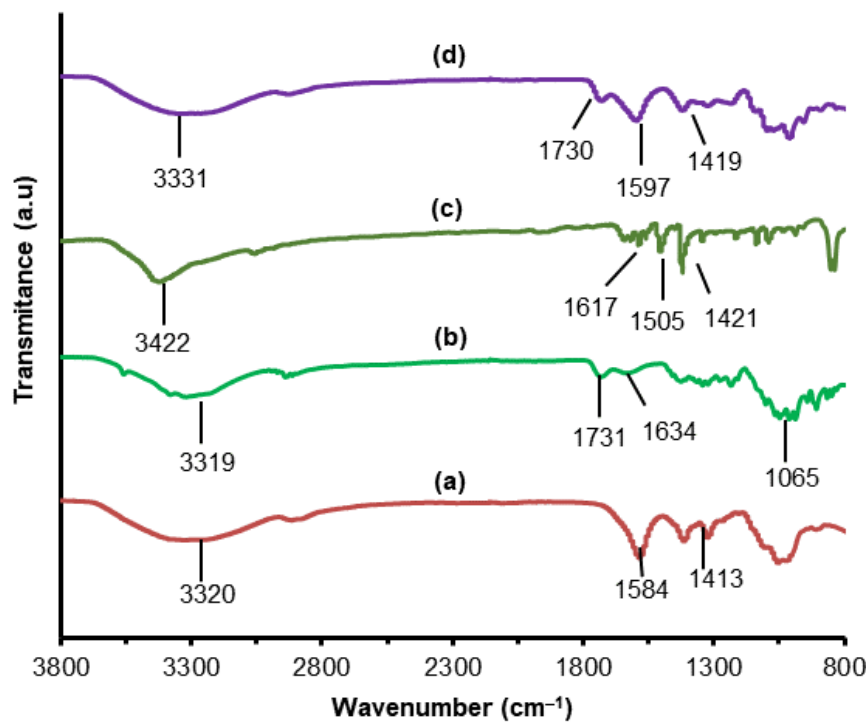

Fig 1. FTIR spectra of (a) sodium alginate, (b) pectin, (c) 1,10-phenanthroline, and (d) alginate/pectinphenanthroline films 
charged group, interacted with the alginate/pectin film through electrostatic interaction. Fig. 2 showed the proposed immobilization process of 1,10-phenanthroline in alginate/pectin film. There was no significant shifting on the methyl ester, indicating that this functional group did not involve in the interactions of alginate/pectin film with $\mathrm{Ca}^{2+}$ cation. The shifted peak from 3320 to $3331 \mathrm{~cm}^{-1}$ exhibited an overlap between the stretching of $\mathrm{OH}$ groups in the alginate/pectin polymers and the 1,10phenanthroline spectrum.

The nature of alginate and pectin were known to be very hydrophilic since they consisted of many $-\mathrm{OH}$ and $-\mathrm{COOH}$ groups. The presence of divalent cations, such as $\mathrm{Ca}^{2+}$, replaced the $\mathrm{Na}^{+}$ions in the sodium alginate and caused the polymer chains of alginate/pectin to cross-link [18]. This process increased the mechanical strength of alginate/pectin film, reducing its dissolution in water; however, it still has the ability to swelling. The film must be able to undergo the swelling process so that the $\mathrm{Fe}(\mathrm{II})$ ion presented in the solution may diffuse into the matrix in order to interact with the 1,10-phenanthroline reagent that is bound to the film matrix. In addition, films formed only from alginate are very soft, brittle, easily dissolve in water but visually more transparent than alginate/pectin films. In contrast, films made only from pectin are rigid but have yellow in color. The mixture of alginate and pectin then produces a stronger, more stable, and transparent film. The transparency of the alginate/pectin film must be preserved because the absorbance of the film will be measured using a UV-Vis spectrophotometer.

\section{SEM Characterization of Alginate/Pectin- Phenanthroline Film}

The morphology of alginate/pectinphenanthroline films before (Fig. 3(a)) and after sensing (Fig. 3(b)) $\mathrm{Fe}(\mathrm{II})$ ion was analyzed using the SEM instrument. The irregular surface shape and some pores were observed on the alginate/pectin-phenanthroline films before Fe(II) sensing (see Fig. 3(a)). This was due to the crosslinking process that did not occur in all polymer chains [17]. After the addition of $\mathrm{Fe}$ (II) ion, the film morphology slightly changed in the formation of 1,10-phenanthroline-Fe(II) complexes causing the surface to be more dense and compact (see Fig. 3(b)) [19]. In addition, some agglomerates were observed, indicating the distribution of 1,10-phenanthroline$\mathrm{Fe}(\mathrm{II})$ complexes.

Table 1 shows the results of the SEM-EDS analysis

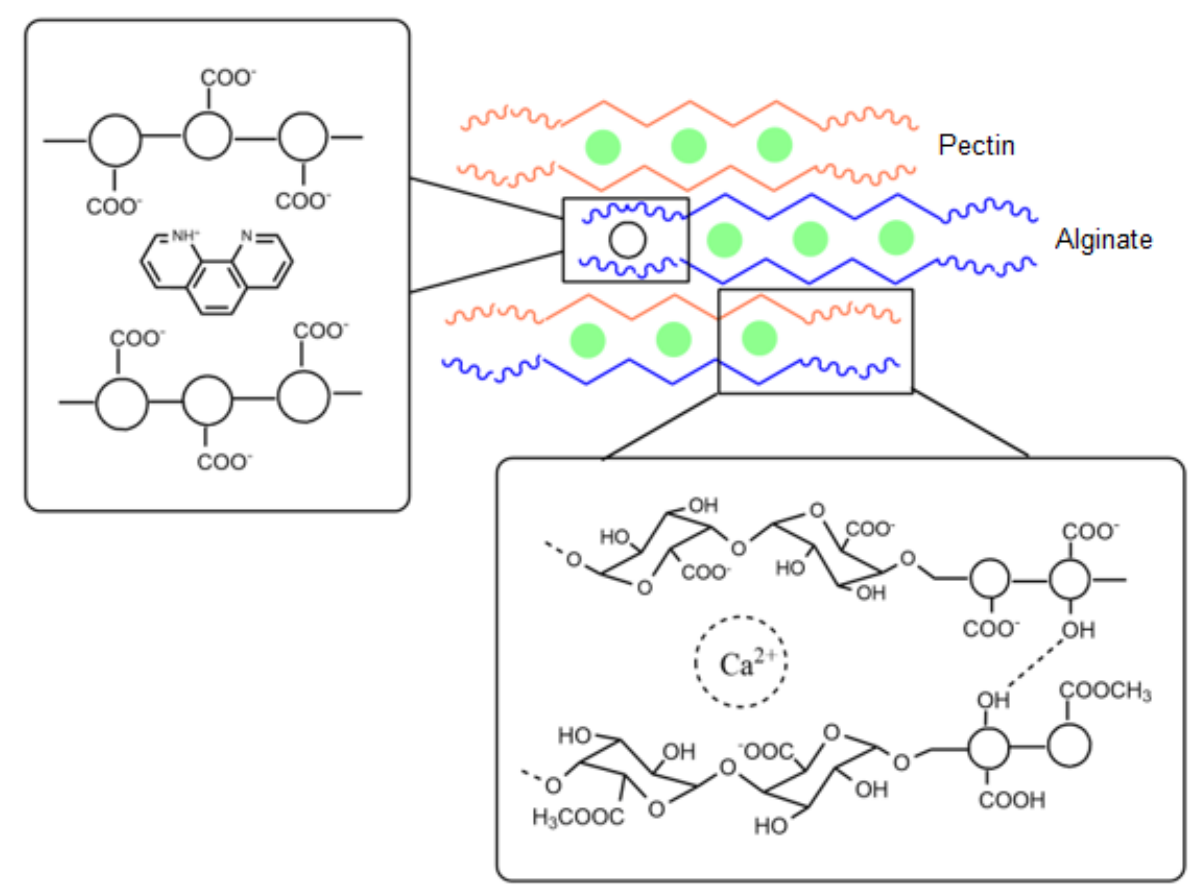

Fig 2. Proposed interaction between alginate/pectin matrix and 1,10-phenanthroline 

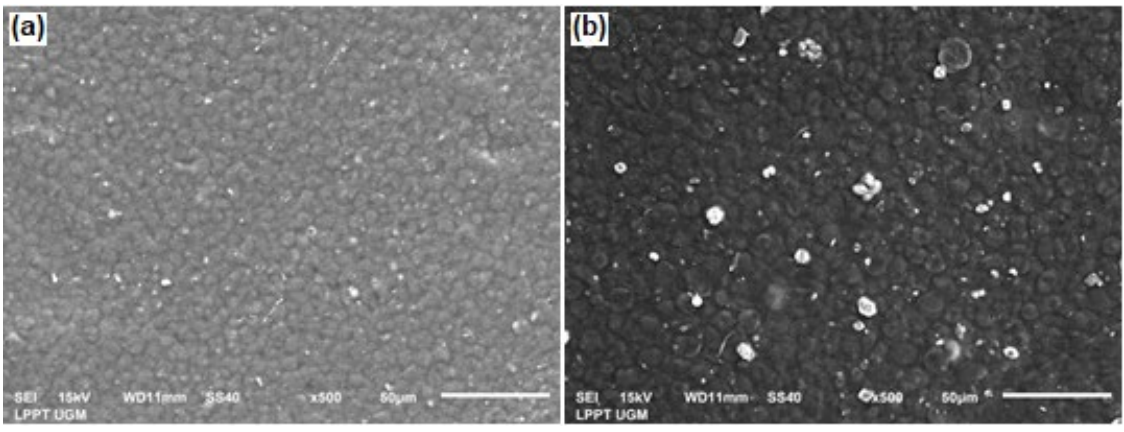

Fig 3. SEM image of alginate/pectin-phenanthroline films (a) before and (b) after sensing with $\mathrm{Fe}(\mathrm{II})$ ion

Table 1. Results of EDS analysis of alginate/pectin-phenanthroline films

\begin{tabular}{cccccc}
\hline & Before sensing & \multicolumn{3}{c}{ After sensing } \\
\hline Element & \% Mass & \% Atom & Element & \% Mass & \% Atom \\
\hline $\mathrm{C}$ & 34.88 & 42.64 & $\mathrm{C}$ & 34.78 & 42.70 \\
$\mathrm{O}$ & 60.73 & 55.74 & $\mathrm{O}$ & 60.15 & 55.44 \\
$\mathrm{Ca}$ & 4.16 & 1.53 & $\mathrm{Ca}$ & 5.04 & 1.85 \\
$\mathrm{Cl}$ & 0.23 & 0.10 & $\mathrm{Fe}$ & 0.02 & 0.01 \\
\hline
\end{tabular}

of alginate/pectin-phenanthroline films before and after the sensing process. The presence of Fe(II) ions can be proven through the data from the EDS (Energy Dispersive $\mathrm{X}$-ray Spectroscopy) analysis. The presence of Fe can be seen in the alginate/pectin-phenanthroline film after the sensing process, even though the amount (\% mass) is relatively small $(0.02 \%)$. The amount of Fe element in the film is very small compared to the amount of $\mathrm{C}$ and $\mathrm{O}$ elements, which are the key elements of the alginate/pectin film. Other elements such as $\mathrm{Ca}$ and $\mathrm{Cl}$ contained in the alginate/pectin-phenanthroline film are derived from $\mathrm{CaCl}_{2}$, which acts as a crosslinking agent.

\section{Optimization of the Condition for Fe(II) Ions Detection Using Alginate/Pectin-Phenanthroline Film}

The principle of the colorimetric method was based on the formation of a complex between the chromogenic reagent and the analyte. In this study, 1,10phenanthroline was used as the chromogenic reagent and immobilized in alginate/pectin films, while the analyte was $\mathrm{Fe}(\mathrm{II})$ ions. Therefore, when the alginate/pectinphenanthroline film was contacted with $\mathrm{Fe}(\mathrm{II})$ ions, the orange-red color of the complexes formed was observed. Although the formation of phenanthroline-Fe(II) complexes was observed by naked-eye (qualitative analysis), the UV-Vis spectrophotometer analysis was performed by quantitative measurement. The maximum absorption wavelength of the phenanthroline-Fe(II) complex formed at $513 \mathrm{~nm}$ (see Fig. 4) was not significantly different from the previous study found at 510-515 nm [3,20].

It was well known that the nature of the chromogenic reagent and the metal ions depended on the $\mathrm{pH}$ of the aqueous system. Therefore, the 1,10phenanthroline and $\mathrm{Fe}(\mathrm{II})$ ions formed a soluble and stable complex in the $\mathrm{pH}$ range 2-9 [20-21]. However, at

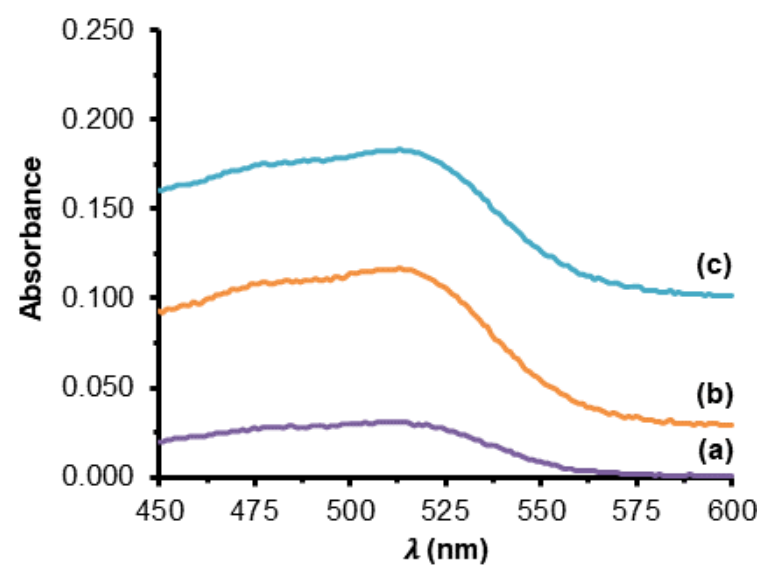

Fig 4. UV-Vis spectra of alginate/pectin-phenanthroline film after the addition of $\mathrm{Fe}(\mathrm{II})$ ion at the concentrations of (a) 2, (b) 5, and (c) $10 \mathrm{mg} \mathrm{L}^{-1}$ 
pH above 4, $\mathrm{Fe}(\mathrm{II})$ ion reacted with $\mathrm{OH}^{-}$to form $\mathrm{Fe}(\mathrm{OH})^{+}$ and the insoluble $\mathrm{Fe}(\mathrm{OH})_{2}$, which blocked the active site of the film, resulting in the decrease of absorbance. Fig. 5 showed that the highest absorbance was achieved at $\mathrm{pH} 2$. At $\mathrm{pH} 3$ and 4 , the amount of protonated 1,10phenanthroline is less than at $\mathrm{pH}$ 2. The unprotonated form of 1,10-phenanthroline tends to leach into the solution and react with free $\mathrm{Fe}(\mathrm{II})$ ions forming $\left[\mathrm{Fe}(\mathrm{II})(\mathrm{phen})_{3}\right]^{2+}$ in the solution. This phenomenon causes a decrease in the absorbance of the alginate/pectin film. However, at a very strong acidic solution $(\mathrm{pH}=1)$, the amount of $\mathrm{H}^{+}$in the solution is huge compared to the amount of $\mathrm{Fe}(\mathrm{II})$ ions, thus lowering the affinity of the 1,10-phenanthroline present in the film to react with $\mathrm{Fe}(\mathrm{II})$ ions.

The optimum concentration (in wt/v) of 1,10phenanthroline was determined by varying the solution in the alginate/pectin films. Meanwhile, the films' capacity depended on the number of carboxyl groups (anions) that interacted with phenanthroline. Fig. 6 showed that the highest absorbance of the films was found in $0.2 \% 1,10$ phenanthroline. This indicated that there were still negative charges in the alginate/pectin film, which have not bound for the optimal formation of complexes between $\mathrm{Fe}(\mathrm{II})$ ion and phenanthroline. This absorbance reached a plateau at a concentration of $0.2-0.3 \%$ since all the negative charges of alginate/pectin have been bound to 1,10-phenanthroline. The effect of the sensing method was also studied by the varying contact time between 0 to $2 \mathrm{~min}$. The result showed that $2 \mathrm{~min}$ was sufficient to give a measurable absorbance of the color changes in alginate/pectin-phenanthroline films (see Fig. 7). This indicated that the films were suitable as a rapid optical sensor agent for $\mathrm{Fe}(\mathrm{II})$ detection.

\section{Interference Study of $\mathrm{Fe}$ (II) lons Detection in the Presence of Other Metal Ions}

The main purpose of preparing the alginate/pectinphenanthroline film as the optical sensor was to detect $\mathrm{Fe}(\mathrm{II})$ ions in environmental samples, especially on surface water. Therefore, some of the interference of metal ions that were present in the water samples became very important to be considered. This was due to the other metal ions that also reacted with 1,10-phenanthroline, lowering its ability to bind $\mathrm{Fe}(\mathrm{II})$ ions. This study was carried out using three different concentrations $\left(5,10\right.$, and $\left.20 \mathrm{mg} \mathrm{L}^{-1}\right)$ of

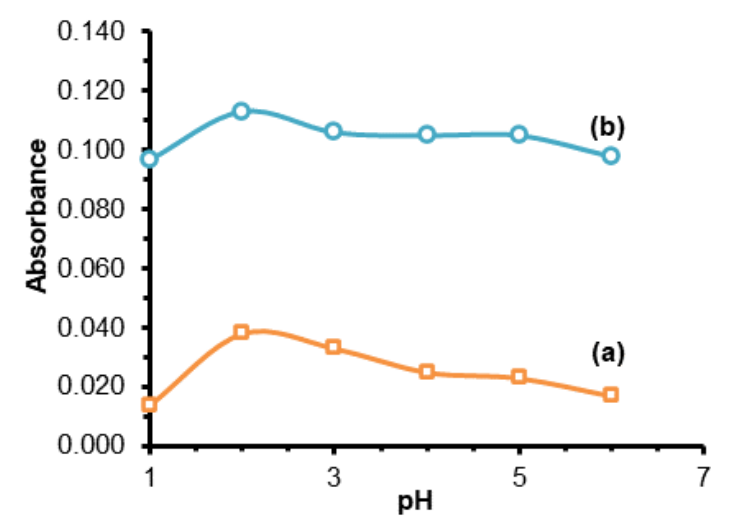

Fig 5. The effect of $\mathrm{pH}$ solution on the absorbance of alginate/pectin-phenanthroline films when the $\mathrm{Fe}$ (II) concentrations were (a) 2 and (b) $8 \mathrm{mg} \mathrm{L}^{-1}$

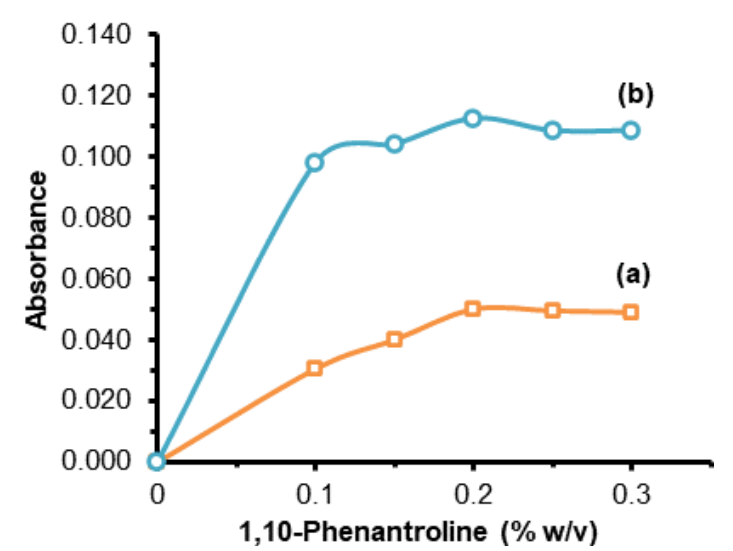

Fig 6. The influence of 1,10-phenanthroline concentration on the absorbance of alginate/pectin-phenanthroline films, when the used $\mathrm{Fe}$ (II) concentration was (a) 2 and (b) $8 \mathrm{mg} \mathrm{L}^{-1}$

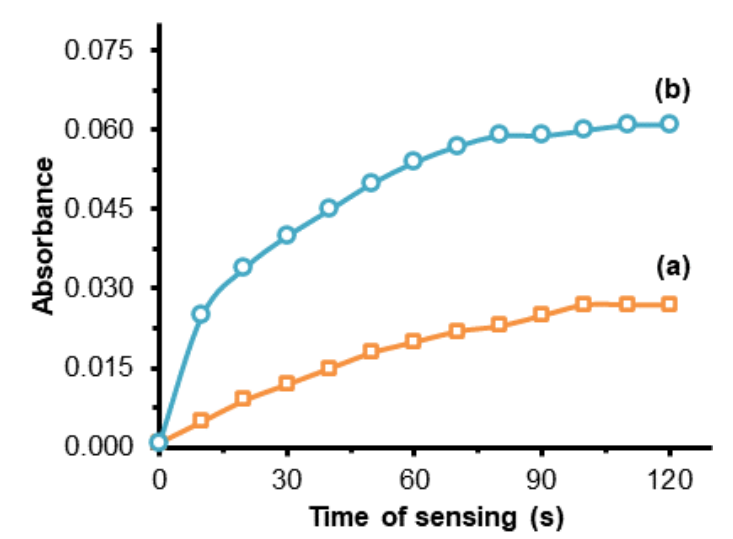

Fig 7. Optimization time of sensing when the used Fe(II) concentration was (a) 2 and (b) $4 \mathrm{mg} \mathrm{L}^{-1}$ 
interference ions, such as $\mathrm{Pb}(\mathrm{II}), \mathrm{Ni}(\mathrm{II}), \mathrm{Fe}(\mathrm{III}), \mathrm{Cu}(\mathrm{II})$, $\mathrm{Zn}(\mathrm{II}), \mathrm{Co}(\mathrm{II}), \mathrm{Mg}(\mathrm{II})$, and $\mathrm{Ca}(\mathrm{II})$, in $25 \mathrm{~mL}$ solution while $\mathrm{Fe}(\mathrm{II})$ was fixed at $5 \mathrm{mg} \mathrm{L}^{-1}$. As shown in Fig. 8, the addition of various interference metal ions except for $\mathrm{Fe}(\mathrm{III})$ ion. It did not significantly influence the Fe(II) ions detection using alginate/pectin-phenanthroline film. Even though some metal ions existed at 4 times higher concentration than $\mathrm{Fe}(\mathrm{II})$ ions, the absorbance value of the films tends to be constant, demonstrating a good selectivity for $\mathrm{Fe}$ (II) detection. However, Fe(III) ions influence the $\mathrm{Fe}$ (II) detection due to their similar cationic size and physicochemical properties. To overcome this problem, the $\mathrm{Fe}(\mathrm{III})$ ions were reduced first using hydroxylamine hydrochloride at $\mathrm{pH} 2$ solution. Therefore, the total $\mathrm{Fe}$ ions concentration at the environmental samples was measured.

\section{Calibration Curve and Sensitivity of Alginate/ Pectin-Phenanthroline Film for Fe(II) Quantification}

Using the optimum condition for Fe(II) detection (i.e., 2 min contact time at $\mathrm{pH} 2$ solution with $0.2 \% \mathrm{wt} / \mathrm{v}$ of 1,10-phenanthroline), a linear calibration curve with

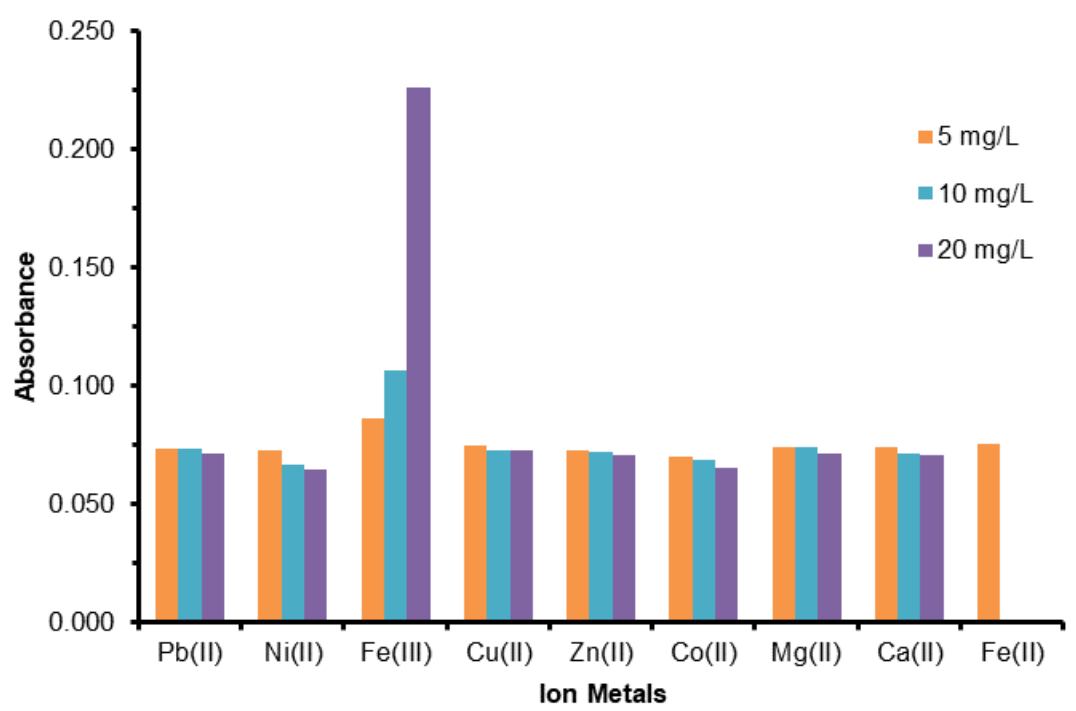

Fig 8. The colorimetric response of alginate/pectin-phenanthroline films in various concentrations of interference metal solution $\left(5,10\right.$, and $\left.20 \mathrm{mg} \mathrm{L}^{-1}\right)$. The concentration of $\mathrm{Fe}(\mathrm{II})$ ion was fixed at $5 \mathrm{mg} \mathrm{L}^{-1}$ in all solutions
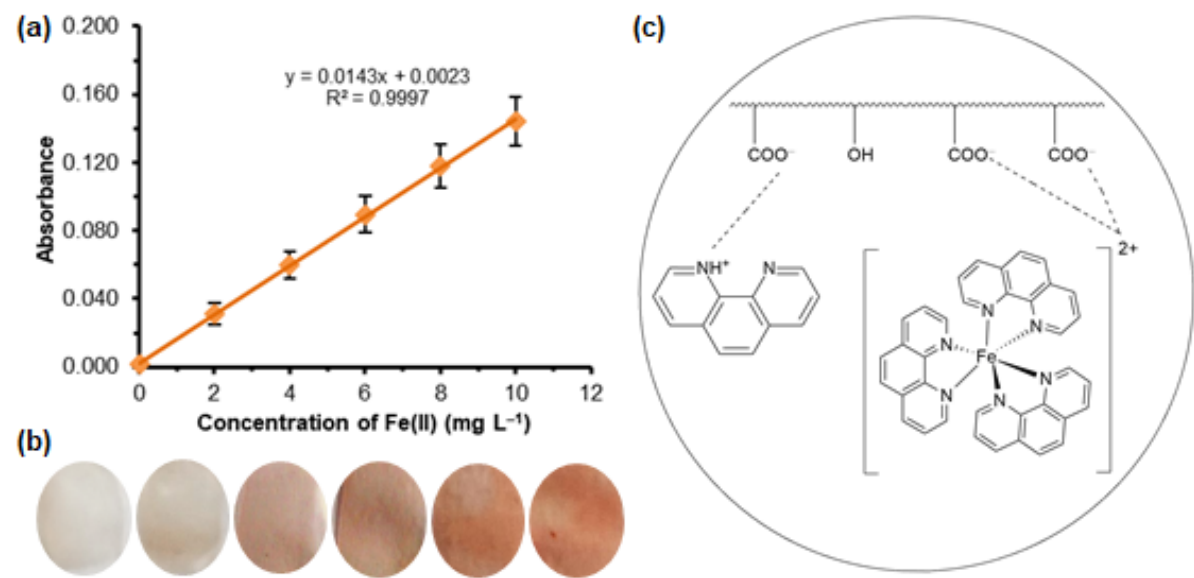

Fig 9. (a) Calibration curve of alginate/pectin-phenanthroline films at various Fe(II) concentrations, (b) the corresponding color of the alginate/pectin-phenanthroline films. From left to right, the concentration of Fe(II) solution was $0,2,4,6,8$, and $10 \mathrm{mg} \mathrm{L}^{-1}$, respectively, and (c) proposed interaction between alginate/pectin matrix and $\left[\mathrm{Fe}(\mathrm{II})(\mathrm{phen})_{3}\right]^{2+}$ 
high $\mathrm{R}^{2}(0.997)$ in the range concentration of $\mathrm{Fe}(\mathrm{II}) 0-10$ $\mathrm{mg} \mathrm{L}^{-1}$ was obtained (Fig. 9(a)). The corresponding color of the alginate/pectin-phenanthroline films and proposed interaction between alginate/pectin matrix and $\left[\mathrm{Fe}(\mathrm{II})(\text { phen })_{3}\right]^{2+}$ are shown in Fig. 9(b) and (c), respectively. The limit of detection for $\mathrm{Fe}$ (II) ions (0.446 $\left.\mathrm{mg} \mathrm{L}^{-1}\right)$ was remarkable. The precision of the quantification method was evaluated by testing the repeatability of the sensor films. The colorimetric response of the films was measured with 3 repetition tests in 3 different batches. Based on the statistical method, the relative standard deviation (RSD) of the different batches were range from $0.70-3.13 \%$, indicating good precision of the proposed method.

\section{Detection of $\mathrm{Fe}$ (II) lons in the Tap Water Sample Using Alginate/Pectin-Phenanthroline Film}

The applicability of the film sensor was performed by determining the $\mathrm{Fe}$ (II) concentration in the tap water sample. Tap water samples were analyzed using atomic absorption spectrometry, resulting in concentrations of $\mathrm{Ca}, \mathrm{Fe}, \mathrm{Mg}, \mathrm{K}$, and $\mathrm{Na}$ ions of 7.0, 0.04, 4.9, 9.5, $63.1 \mathrm{ppm}$, respectively. The sample was spiked with $\mathrm{Fe}(\mathrm{II})$ standard solution at 2, 5, and $10 \mathrm{mg} \mathrm{L}^{-1}$, then measured using a UVVis spectrophotometer in optimum condition. Table 2 showed that the films sensor had good \% recoveries between $102.10-110.72 \%$, indicating a good accuracy for $\mathrm{Fe}(\mathrm{II})$ detection. The range of $\%$ recoveries value obtained was in accordance with that of the sample category in ppm units, between $80-110 \%$ [22]. This showed that the presence of other disruptive matrices or other interferent metal ions in the tap water sample did not affect the detection of $\mathrm{Fe}(\mathrm{II})$ ions using alginate/pectinphenanthroline films. However, there was a possibility that $\mathrm{Fe}$ (III) ions were contained in the tap water sample and might affect the detection of $\mathrm{Fe}(\mathrm{II})$. To overcome this problem, the tap water sample needed to be treated with hydroxylamine hydrochloride, causing the total $\mathrm{Fe}$ ions in the tap water sample to be in the form of $\mathrm{Fe}(\mathrm{II})$ ions for its detection to be optimal.

In addition, we have also compared the performance of the present sensor film with the other sensors available in the literature (Table 3 ). It can be seen that the detection of $\mathrm{Fe}$ (II) using alginate/pectinphenanthroline film is promising to be an alternative method of $\mathrm{Fe}(\mathrm{II})$ in the water sample. Alginate/pectin film could be easily degraded in the environment. It makes this research has more advantage than other sensors. In addition, the complicated stages of reagent

Table 2. Determination of Fe(II) ion concentration in tap water sample using alginate/pectin-phenanthroline film in the optimum condition

\begin{tabular}{ccc}
\hline $\mathrm{Fe}(\mathrm{II})$ added $\left(\mathrm{mg} \mathrm{L}^{-1}\right)$ & $\mathrm{Fe}(\mathrm{II})\left(\mathrm{mg} \mathrm{L}^{-1}\right)$ & \% recovery \\
\hline 0 & 0.469 & - \\
2 & 2.683 & 110.72 \\
5 & 5.667 & 103.96 \\
10 & 10.678 & 102.10 \\
\hline
\end{tabular}

Table 3. Comparison of performance of different Fe sensors with the presence sensor

\begin{tabular}{|c|c|c|c|c|}
\hline Analyte & Method & Medium & $\begin{array}{l}\text { LOD } \\
\left(\mathrm{mg} \mathrm{L}^{-1}\right)\end{array}$ & Ref. \\
\hline $\mathrm{Fe}(\mathrm{II})$ & Potentiometric determination & $\begin{array}{l}\text { Solid probe (2, 6-bis (carboxamide methyl ester) } \\
\text { pyridine derivative as neutral ionophore in } \\
\text { plasticized PVC membrane) }\end{array}$ & 0.224 & [9] \\
\hline $\mathrm{Fe}(\mathrm{II})$ & $\begin{array}{l}\text { UV-Vis absorption of } \mathrm{Fe}-2- \\
\text { (2-pyridyl) imidazole complex }\end{array}$ & $\begin{array}{l}\text { Solid probe (2-(2-pyridyl)imidazole functionalize } \\
\text { poly(vinylbenzyl chloride) (PVBC) nanofibers } \\
\text { made into membrane) }\end{array}$ & 2.0 & [23] \\
\hline $\mathrm{Fe}(\mathrm{III})$ & Naked eye observation & Solid Probe (Curcumin loaded in Zein membrane) & 0.40 & {$[24]$} \\
\hline $\mathrm{Fe}(\mathrm{II} \& \mathrm{III})$ & $\begin{array}{l}\text { UV-Vis absorption of Fe-1,10- } \\
\text { phenanthroline complex }\end{array}$ & $\begin{array}{l}\text { Solid probe }(1,10 \text {-phenantrhroline entrapped in } \\
\text { poly(acrylamide) membrane) }\end{array}$ & 0.02 & {$[3]$} \\
\hline $\mathrm{Fe}(\mathrm{II})$ & $\begin{array}{l}\text { UV-Vis absorption of Fe-1,10- } \\
\text { phenanthroline complex }\end{array}$ & $\begin{array}{l}\text { Solid probe (1,10-phenanthroline entrapped in } \\
\text { alginate/pectin film) }\end{array}$ & 0.446 & $\begin{array}{c}\text { Present } \\
\text { work }\end{array}$ \\
\hline
\end{tabular}


syntheses did not require for this study. The 1,10phenanthroline reagents can be obtained easily and react very selectively with Fe(II) ion compared to other metal ions.

\section{- CONCLUSION}

The alginate/pectin-phenanthroline film optical sensors were successfully prepared by immobilizing 1,10 phenanthroline in alginate/pectin films. The optimum condition for $\mathrm{Fe}(\mathrm{II})$ detection was obtained at $\mathrm{pH} 2$ for 2 min contact time and $0.2 \%$ of 1,10 -phenanthroline concentration. The alginate/pectin-phenanthroline provided high accuracy, precision, and selectivity for $\mathrm{Fe}$ (II) in the aquatic environmental samples, with a detection limit of $0.446 \mathrm{mg} \mathrm{L}^{-1}$. Therefore, the alginate/ pectin-phenanthroline film optical sensor was found as a simple, fast, accurate, and alternative method for $\mathrm{Fe}(\mathrm{II})$ ions detection in the environmental samples for routine daily analysis.

\section{- ACKNOWLEDGMENTS}

The authors are grateful to the Directorate of Research of Universitas Gadjah Mada for funding this study through the RTA (Final Project Research) Scheme.

\section{- REFERENCES}

[1] Chakrabarty, S., Tonu, N.T., and Saha, N.K., 2018, Removal of iron(II) ion from aqueous solution using waste tea leaves, Int. J. Eng. Sci., 6 (12), 62-67.

[2] World Health Organization, 1996, Guidelines for Drinking Water, Geneva.

[3] Kumar, S.A., Thakur, N., Parab, H.J., Pandey, S.P., Shinde, R.N., Pandey, A.K., Kumar, S.D., and Reddy, A.V.R., 2014, A visual strip sensor for determination of iron, Anal. Chim. Acta, 851, 87-94.

[4] Pavlovska, G., Stafilov, T., and Čundeva, K., 2015, Determination of iron in drinking water after its flotation concentration by two new dithiocarbamate collectors, J. Environ. Sci. Health. Part A Environ., 50 (13), 1386-1392.

[5] Adebayo, B.K., Ayejuyo, S., Okoro, H.K., and Ximba, B.J., 2011, Spectrophotometric determination of iron(III) in tap water using 8-hydroxyquinoline as a chromogenic reagent, Afr. J. Biotechnol., 10 (71), 16051-16057.

[6] Poirier, L., Nelson, J., Leong, D., Berhane, L., Hajdu, P., and Lopez-Linares, F., 2016, Application of ICPMS and ICP-OES on the determination of nickel, vanadium, iron, and calcium in petroleum crude oils via direct dilution, Energy Fuels, 30 (5), 3783-3790.

[7] Lou, T., Chen, L., Chen, Z., Wang, Y., Chen, L., and Li, J., 2011, Colorimetric detection of trace copper ions based on catalytic leaching of silver-coated gold nanoparticles, ACS Appl. Mater. Interfaces, 3 (11), 4215-4220.

[8] Murthy, Y.L.N., Govindh, B., Diwakar, B.S., Nagalakshmi, K., and Singh, R., 2011, A simple inexpensive detection method of nickel in water using optical sensor, Int. J. ChemTech. Res., 3 (3), 1285-1291.

[9] Abounassif, M.A., Al-Omar, M.A., Amr, A.G.E., and Mostafa, G.A.E., 2011, PVC membrane sensor for potentiometric determination of iron(II) in some pharmaceutical formulations based on a new neutral ionophore, Drug Test. Anal., 3 (6), 373-379.

[10] Galus, S., and Lenart, A., 2013, Development and characterization of composite edible films based on sodium alginate and pectin, J. Food Eng., 115 (4), 459-465.

[11] Bierhalz, A.C.K., da Silva, M.A., and Kieckbusch, T.G., 2012, Natamycin release from alginate/pectin films for food packaging applications, J. Food Eng., 110 (1), 18-25.

[12] Rezvanian, M., Ahmad, N., Mohd Amin, M.C.I., and Ng, S., 2017, Optimization, characterization, and in vitro assessment of alginate-pectin ionic cross-linked hydrogel film for wound dressing applications, Int. J. Biol. Macromol., 97, 131-140.

[13] Hua, S., Ma, H., Li, X., Yang, H., and Wang, A., 2010, pH-sensitive sodium alginate/poly(vinyl alcohol) hydrogel beads prepared by combined $\mathrm{Ca}^{2+}$ crosslinking and freeze-thawing cycles for controlled release of diclofenac sodium, Int. J. Biol. Macromol., 46 (5), 517-523.

[14] Coimbra, P., Ferreira, P., de Sousa, H.C., Batista, P., Rodrigues, M.A., Correia, I.J., and Gil, M.H., 2011, 
Preparation and chemical and biological characterization of a pectin/chitosan polyelectrolyte complex scaffold for possible bone tissue engineering applications, Int. J. Biol. Macromol., 48 (1), 112-118.

[15] Fayad, N.K., Al-Noor, T.H., Mahmood, A.A., and Malih, I.K., 2013, Synthesis, characterization, and antibacterial studies of $\mathrm{Mn}(\mathrm{II}), \mathrm{Fe}(\mathrm{II}), \mathrm{Co}(\mathrm{II}), \mathrm{Ni}(\mathrm{II})$, $\mathrm{Cu}$ (II) and $\mathrm{Cd}$ (II) mixed-ligand complexes containing amino acid (L-valine) and (1,10-phenanthroline), Chem. Mater. Res., 3 (5), 66-74.

[16] Smith, R.C., 1961, Infrared Spectra of Substituted 1,10-Phenanthrolines, Dissertation, Department of Chemistry Iowa University, Iowa, USA.

[17] Aguilar, K.C., Tello, F., Bierhalz, A.C.K., Romo, M.G.G., Flores, H.E.M., and Grosso, C.R.F., 2015, Protein adsorption onto alginate-pectin microparticles and films produced by ionic gelation, J. Food Eng., 154, 17-24.

[18] Awasthi, R., Kulkarni, G.T., Ramana, M.V., Pinto, T.J.A., Kikuchi, I.S., Ghisleni, D.D.M., Braga, M.S., and Dua, K., 2017, Dual crosslinked pectin-alginate network as sustained release hydrophilic matrix for repaglinide, Int. J. Biol. Macromol., 97, 721-732.
[19] Siracusa, V., Romani, S., Gigli, M., Mannozzi, C., Cecchini, J.P., Tylewicz, U., and Lotti, N., 2018, Characterization of active edible films based on citral essential oil, alginate and pectin, Materials, 11 (10), 1980.

[20] Wang, L., Zhang, Y., Park, Y., Chen, L., and Jung, Y.M., 2017, Quantitative determination of iron ions based on a resonance, Anal. Sci., 33 (1), 23-27.

[21] Adhikamsetty, R.K., Gollapalli, N.R., and Jonnalagadda, S.B., 2008, Complexation kinetics of $\mathrm{Fe}^{2+}$ with 1,10-phenanthroline forming ferroin in acidic solutions, Int. J. Chem. Kinet., 40 (8), 515523.

[22] Harris, D.C., 2010, Quantitative Chemical Analysis, W.H. Freeman and Company, New York, USA.

[23] Ondigo, D.A., Tshentu, Z.R., and Torto, N., 2013, Electrospun nanofiber based colorimetric probe for rapid detection of $\mathrm{Fe}^{2+}$ in water, Anal. Chim. Acta, 804, 228-234.

[24] Saithongdee, A., Praphairaksit, N., and Imyim, A., 2014, Electrospun curcumin-loaded zein membrane for iron(III) ions sensing, Sens. Actuators, B, 202, 935-940. 